\title{
“Comfort” as a Critical Success Factor in Blended Learning Courses
}

\author{
Linda S. Futch, Aimee deNoyelles, Kelvin Thompson, Wendy Howard \\ University of Central Florida
}

\begin{abstract}
There are substantial quantitative research and anecdotal reports on blended learning and blended learning courses. However, few research studies focus on what happens at the classroom level. This research study aims to consider the highly contextual environment of effective blended learning courses by identifying the strategies instructors use to unify the face-to-face and online components of their courses to support student success. Using a case study model, interviews were conducted with three community college instructors who were identified as exemplary teachers of blended learning courses in their institutions. The research questions explored in this article are: (R1) What are exemplary community college teachers' perceived obstacles to student success in blended courses? and (R2) What solutions or strategies do exemplary community college teachers employ to overcome perceived obstacles to student success in blended courses? The interviews were analyzed by the researchers to identify descriptive themes and sub-themes related to student success. It was found that "comfort" emerged as a mediating factor for student success, with "organization," "communication," and "support" acting as supporting themes. These findings will be reported as pedagogical strategies and scalable best practices for the design of blended courses that promote student success.
\end{abstract}




\section{Introduction}

While both community colleges and universities offer higher educational opportunities for learners, there are some influential differences between the two contexts. The policies for community college admission are traditionally more open than comparable policies for universities, and community colleges typically support a student population that is more "non-traditional" in nature (Bailey, Calcagno, Jenkins, Kienzl \& Leinbach, 2005). A pressing concern of community colleges are the issues of student retention and completion, as many students do not finish a degree (Bailey et al., 2005). From the instructor perspective, it is challenging to support a diverse body of students who exhibit differing academic preparedness and to successfully retain them through the academic program. Community colleges usually offer services designed to support at-risk students quests for success in the educational arena (Cohen \& Brawer, 1996).

Blended course offerings have been on the rise in community colleges (Dembicki, 2011). Over the last decade of research, no universal definition of the term 'blended learning” has emerged.' At its most basic, blended learning combines elements of face-to-face and online modalities regarding content and delivery (McGee \& Reis, 2012). Moskal, Dziuban, and Hartman (2013) explain that the concept of blended learning is not universal because it is fundamentally interdependent with the context in which it occurs. They note characteristics such as the mission of the institution, faculty responsiveness, and institution support, among others are critical to framing the concept. These parameters allow institutions to develop courses and programs that work best for their own populations. Dziuban, Hartman, and Moskal (2004) declare, "Blended learning should be viewed as a pedagogical approach that combines the effectiveness and socialization opportunities of the classroom with the technologically enhanced active learning possibilities of the online environment, rather than a ratio of delivery modalities” (p. 3). Offering more blended options seems appropriate for community colleges, which strive to offer flexible options for their diverse populations of learners. Also, blended courses may allow instructors, whose main responsibility is supporting student success through effective teaching, to enhance the design of the teaching and learning environments.

The research questions explored in this article are:

R1. What are exemplary community college teachers' perceived obstacles to student success in blended courses?

R2. What solutions or strategies do exemplary community college teachers employ to overcome perceived obstacles to student success in blended courses?

This research study aims to consider the highly contextual environment of effective blended learning courses and strategies teachers use to unify the face-to-face and online components of their courses to support student success. We first present a preliminary model that emerged from interviews with exemplary teachers. After sharing the findings, we present a modified model based on a deeper analysis followed by implications and next steps for future research.

\section{Student Success in Blended Learning in Community College Settings}

Research literature pertaining to student success in blended learning courses within community college settings was reviewed. Peer-reviewed resources were identified through a search of the Education Full Text library database using the search terms "blended," "hybrid," and "community college." In addition, articles referenced in those resources were also considered for inclusion in review. The search was further refined by scanning the resource to determine if specific instructional or institutional strategies in the community college setting were addressed. Themes that were generated through this review include community college student characteristics, the unique features of the blended environment, and effective support strategies. 
The majority of studies took note of the student characteristics that comprise the community college population. One commonly identified factor is non-traditional age (Brotton, 2005; Crawford, Barker, \& Sevam, 2014), with students generally being older than the traditional college-aged population (18-22 years old). These older students tend to have multiple responsibilities in life, such as employment and family obligations. It has been proposed that offering fully online courses could support these students (Yen \& Liu, 2009). However, high online attrition rates have emerged as a concern, negatively impacting the notion of student success (Traver, Bidjerano \& Shea, 2014; Yen \& Liu, 2009). Factors that could possibly explain this trend are that community college students generally exhibit lower levels of technical experience (Brotton, 2005; Crawford et al., 2014; Lloyd-Smith, 2010; McGee \& Reis, 2012) and lower levels of academic preparedness (Crawford et al., 2014; Johnson et al., 2013; Traver et al., 2014). In a study that compared performance in a community college biology course in both online and face-to-face formats, Wolff, Wood-Kustanowitz, and Ashkenazi (2014) found that the mode of delivery was one of the significant predictors of successful course completion, with the online section performing lower. In a related study, Garman (2012) found that students over the age of 25 experienced a higher success rate in face-to-face courses over online courses. They interpreted this finding in that there is a general lack of strategies for working with community college learners, who may lack the motivation and discipline necessary for success. Increasing technology use will not solve this problem, as students typically exhibit lower levels of technical experience (Johnson et al, 2013).

Blended learning has emerged as a potential solution to address the diverse learning needs of community college students (Lloyd-Smith, 2010). Xu and Jaggars (2011) found that students enrolled in blended courses were similar to those enrolled in face-to-face classes and were equally likely to complete their course. Crawford et al. (2014) found that community college students generally do as well in blended courses as in face-to-face courses. The blended format allows for social connections to be built that enhance communication, thereby supporting student retention and success (Hijazi, Crowley, Smith, \& Shaffer, 2006). Cruz-Johnson (2012) noted that the blended format may support participants with multiple learning styles more than the traditional face-to-face setting. By its very nature, the blended environment requires that learners display more independence and autonomy (McGee \& Reis, 2012) and self-regulated learning in order to be successful. Yen and Liu (2009) examined the relationships between autonomy (exhibiting intentional behavior in learning activities) and final grades in community college online courses and found that autonomy was a predictor of success and final grades. They recommend more blended learning courses to support learner autonomy. In summary, blended learning calls for autonomy while simultaneously offering services that may support students who are less technically and/or academically prepared.

Reducing student barriers is critical in order for student success to be realized (McGee \& Reis, 2012). In a case study about redesigning for a blended course, Brotton (2005) found that the few students who had previously taken online courses did not experience barriers, but the others with no prior experience required extra help. Offering an orientation can prepare students to navigate the online and face-to-face components (Shand, Glassett Farrelly, \& Costa, 2016). Brotton, along with McGee and Reis (2012) and Traver et al. (2014) suggest that students gained confidence using the online components when given an initial introduction within the classroom setting. Providing support for online technology increases participation and reduces attrition (McGee \& Reis, 2012). In addition, students who have previously taken more than one online or blended course tended to experience more social, cognitive and teaching presence than learners new to the blended environment (Traver et al., 2014). New students will need support in this area. Also, a later study by Shea and Bidjerano (2014) indicates a changing trend. They found online and distant courses provided a more efficient and effective path to graduation and students were more likely to complete a four-year degree. 
Blended courses can be effective in promoting student success, but only if designed and delivered with care. Traver et al. (2014) cautioned how poor online course design is a factor that contributes to the high attrition rate. Instructors often find difficulty finding the right "blend" of online and face-to-face components (Ma'arop \& Embi, 2016). Some indicators of excellent blended teaching are facilitating student learning, communicating ideas effectively, demonstrating an interest in learning, organizing effectively, showing respect for students, and assessing progress fairly (Hartman, Moskal, \& Dziuban, 2005). Design should be learner-centered; acknowledging students' diverse abilities and styles contributes to the success of the overall design (McGee \& Reis, 2012; Lai, Lam, \& Lim, 2016; Shand et al., 2016). When designed from the learners' perspectives, retention and success are increased (McGee \& Reis, 2012). Communication of the blended design, expectation, and process are key for student success (McGee \& Reis, 2012). Feedback and interactivity are two elements that promote student engagement in the course (McGee \& Reis, 2012). Manuelito (2013) examined community college students in a blended science course and found that they employed a variety of self-regulated learning strategies to support their learning. Activities that required reflection helped students refine self-regulated learning skills. She suggests that instructors foster learning in blended courses by teaching them to engage in self-regulated learning processes and behaviors rather than focusing merely on delivery of course content. Access to these processes and behaviors gives learners a feeling of greater control over the autonomous areas of blended learning, and in turn, increase success. Clear instructions, manageable assignments, and relevant activities support student responsibility for learning outside of class and participation in class (McGee \& Reis, 2012). Support emerges as a major theme as well. Students and faculty must have the resources and support to strengthen blended learning (Hijazi et al., 2006; Ma'arop \& Embi, 2016). Links to student services and practice activities helps students who may lack sufficient skills (Ma'arop \& Embi, 2016; McGee \& Reis, 2012).

\section{Limitations}

In this relatively new field, there is no consensus on a single definition or unified approach to blended learning within the higher education context. There is a significant body of research on blended learning, but it lacks a center point because it extends across multiple fields and disciplines, and there is a gap in the literature regarding implementation of blended learning (Halverson, Graham, Spring, Drysdale, \& Henrie, 2014). Furthermore, best practices exist, but they are often centered on static course design and not grounded in empirical research. There is a strong need to find strategies, both before the class and during, that can be generalized in an effort to support student success in community college and related higher education settings.

It is important to clarify how "success" was operationally defined in the studies included for review. The majority of studies that offered a definition for "success" (Cruz-Johnson, 2012; Garman, 2012; Porter et al., 2014; Yen \& Liu, 2009) defined it as completing the course with a passing grade (typically a $\mathrm{C}$ or higher). While this definition does provide a standardized baseline in which an institution can measure success (Porter et al., 2014), it would be helpful to conceptualize more nuanced ways of understanding how teachers conceive success, and how their teaching strategies support that type of success.

In addition, most studies that focused on success in blended community college settings were mostly quantitative in nature and based on student data such as exam scores. More attention needs to be given to provide a qualitative look at how teachers understand the notion of success. Traver et al. (2014) recommended that future research should examine the effect of other factors like level of course difficulty, course discipline, GPA, and on community college completion of blended courses. Wolff et al. (2014) suggested that more studies at community colleges are needed, as differences between student bodies have not received enough attention. 


\section{Methodology}

\section{Case Study}

The interviews in this study emerged from a professional development project related to blended learning. If, instead, the study had been designed with no reference to this professional development program, it is possible that a number of methodological decisions would have been made differently. As a result, the context from which this line of inquiry emerged is worth noting.

The interviews in this study are part of a collection of recorded audio interviews associated with a set of open educational resources (OER) called the BlendKit Course (http://bit.ly/blendkit). This interview collection originated in association with a series of massive open online courses (MOOCs) offered as professional development to instructors and designers of blended learning courses (i.e., BlendKit2011, BlendKit2012, BlendKit2014, BlendKit2015, and BlendKit2016).

In the original MOOC cohort (2011), participants were presented with brief, thematic audio segments edited from interviews conducted with experienced blended learning faculty. These segments were the basis for a series of question-and-answer webinars, and the segments were also made available in an online repository. After reviewing these initial recordings, the course designer/facilitator recognized the potential of such interviews for inquiry into the nature of blended learning design and pedagogy. In preparation for a second cohort (2012), the co-facilitators decided to re-frame the interviews as a line of inquiry. The current study was born out of contacts made during those original interviews.

\begin{tabular}{|l|l|}
\hline Table 1 & \\
\hline Timeline & \\
\hline BlendKit2011 & July - August 2011 \\
\hline Revise interview questions & April 2012 \\
\hline Recruit interviewees for BlendKit2012 & May 2012 \\
\hline Record interviews & June 2012 \\
\hline BlendKit2012 & September - October 2012 \\
\hline IRB approval & February 2013 \\
\hline Review recordings for initial bounded case & May - October 2013 \\
\hline Informed consent (comm. college faculty) & October 2013 \\
\hline Transcription & February 2014 \\
\hline Interview data analysis & March - June 2014 \\
\hline Article writing/revision & Intermittent through December 2015 \\
\hline
\end{tabular}

\section{Participant Selection}

For optimal utility as a professional development resource, the 2011 interview collection was formed by reaching out to University of Central Florida faculty known personally to the course designer as successful in teaching blended courses. These interviews were then supplemented by contacting 
colleagues at the University of Wisconsin Milwaukee (an institution with a national reputation for successful blended learning programs) for referrals to additional faculty. In preparation for BlendKit2012, the course facilitators sought to further diversify the interview collection to represent a broader range of institutional contexts. One of the facilitators reached out through professional networks to leaders at other institutions known for success in blended learning. These contacts were asked for referrals to faculty known by them to be effective in teaching blended courses. The identified faculty members were invited to participate in audio interviews as part of the BlendKit2012 course materials. The initial contact message mentioned an optional research component to be discussed at a later date. Interested faculty who were available for interviews within the required time frame were scheduled and recorded. (The interview process is addressed below in a separate section.)

After BlendKit2012, the researchers met to discuss how to best bound an initial set of interviews selected from the entire collection. Recognizing that a number of interviews had been conducted with community college faculty and that community colleges are known for their emphasis on effective teaching and learning, the researchers selected three community college interviews representing different institutions and disciplines (Composition, Spanish, and First-Year Seminar). With a perception that there might be less systematic inquiry and less robust faculty development related to blended teaching in the community college context, the researchers hoped that this line of inquiry would be of particular use to community college faculty and faculty developers as effective practices in blended learning were identified. We contacted each interviewee via email with an informed consent letter approved by the IRB. After consent was received, we proceeded with transcription and analysis of the interviews.

\section{Data Analysis}

The selected interviews were transcribed by three members of the research team. After this initial round, one member compared each transcript with the audio recording to ensure the accuracy of the data source before proceeding with analysis. All members independently read through the transcribed interviews and reconvened for discussion. The interviews were purposefully selected, with the First-Year Seminar being analyzed last, in the hopes that this course, which is more general in terms of academic content, would tease out generalizations to explain the emerging themes in the other two.

A grounded theory approach was employed to analyze the interviews. Grounded theory emphasizes becoming immersed ("grounded") in the data so that embedded meanings and relationships between concepts can emerge ("theory") (Corbin \& Strauss, 2008). For the initial analysis of the first interview (Spanish), the members independently open-coded to reveal emerging themes, noting anything that related to the main research questions (identifying strategies that unify the face-to-face and online elements of blended courses, supporting student success in the community college context). The team then compared, discussed, and calibrated our coding for consistency. Examples of initial codes generated included "conception of blended learning," "course discipline (Spanish)," and "planning." Codes were then organized into three tentative categories: "organization," "communication," and "philosophy.” We then analyzed the second interview (Composition) and continued with independent open coding, but began filing them under the initial codes and categories when appropriate. The theme of "resistance" emerged here, and a connection to the first interview was noted that mentioned student resistance about learning Spanish. At this point, we realized that "comfort/concern” may not be limited to the Spanish discipline. We went to the third interview (First-Year Seminar). Here, a heavy emphasis on student support and success was noted. Thinking about the other themes emerging from the previous interviews (resistance, fear, concern), "support” and “comfort” emerged as new categories.

When this initial analysis of the interviews was complete, the transcripts were analyzed again independently, with consideration for the codes and categories that were developed. Ultimately, four

categories emerged: communication, organization, support, and comfort. We returned to the transcripts in order to flag specific instances of each category, and identify the associated strategy. From these team 
discussions, tables were created for each interview. We listed the Concerns ("mitigate fear of Spanish") and the associated theme with transcript line numbers for reference (“Organization, Line 116-124”). We also noted some emerging ideas from the discussion. For instance, during the Spanish discussion, we attempted to articulate the term of "comfort." "Comfort does not mean easy. Comfort is a means/mediating factor to success." Beyond the obvious, course completion or satisfaction of learning objectives, success was also defined more implicitly by each of the instructors that was more affective in nature (willingness, open-mindedness). Comfort emerged as a mediating factor, rather than being a factor on the same level as Communication, Organization, and Support. The resulting model that is presented in this paper describes the relationships between and among the categories with respect to the nature of student success in blended environments.

\section{Model Development}

\section{Emergence of “Comfort"}

Before we started coding the transcribed interviews, we looked explicitly for examples of organization, communication, and support because these are hallmarks of high quality course design and teaching. We thought that concrete examples of these factors could give rise to design principles or pedagogical practices that might be codified in a pattern language (Alexander, 1977) for blended design and teaching. We did not expect to find this holistic construct we have labeled "comfort." However, during the iterative analysis process, we found that as each instructor employed various strategies related to organization, communication, and support while teaching her blended course, she did so with concern for student "comfort" as she sought student success. Thus, while organization, communication, and support are often associated with the design of courses, "comfort" is related to the actual facilitation (and the students' resultant experience) of the course.

\section{The Model}

We have found it helpful to depict the interrelated constructs being presented (i.e., organization, communication, support, "comfort," and student success) in a graphical model (Figure 1). This model poses that "comfort" is an affective mediating factor of student success in community college environments. We note that student success means different things to different people (e.g., not just completing the course or receiving a "C" or higher as a final course grade). In fact, each of our interview participants seemed to have multiple conceptualizations of success. We have chosen not to define student success rigidly. Rather, we recognize that it is the pursuit of student success as a desirable goal that is most relevant to the model at this point.

When "comfort" is perceived by students, fear and resistance are reduced, and students are more willing to produce, to try, leading to success. Thus, the mediation of "comfort" emphasizes the participative element of student success. 


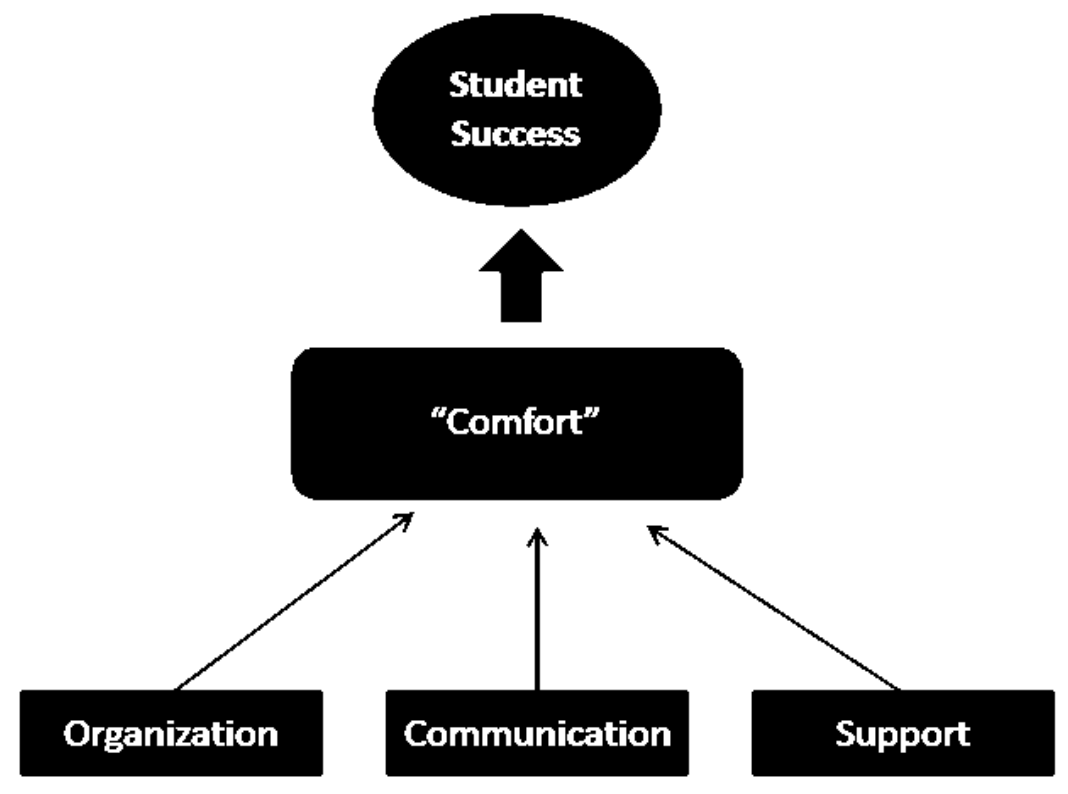

Figure 1. Comfort model showing a graphical depiction of interrelated constructs (i.e., organization, communication, support, "comfort," and student success)

A refined version of this "comfort" model will be presented at the end of the Findings section below. We hope that this model can be confirmed and tested in other blended contexts leading to further refinements.

\section{“Comfort” Defined Operationally}

We recognize the potential provocative nature of the word "comfort" and have heard various colleagues voice sentiments like, "It is not my function as a faculty member to make students comfortable." However, as used by the interviewed instructors, we understand "comfort" as a reducing of students' vulnerabilities, brought about by instructors' design and teaching strategies, so that students are more likely to succeed in their blended courses. For instance, the First-Year Seminar is designed as a gateway to further college success. Thus, a potential threat to students in this course might be expressed in the belief statement, “If I don't succeed in this class, I won't succeed in college!” Meanwhile, with the Spanish and Composition course, the threats are based in discipline-specific fear of failure (i.e., "Writing? I can’t write!” “Spanish? I have to learn another language?”). When listening to the instructors' interviews one can hear the concern of each to mitigate the fears of their students through their course design and their teaching.

\section{Findings}

\section{Organization (Design)}

Course organization emerged as a critical factor related to student comfort and in turn, success. The instructors voiced that when organization is perceived as lacking by students, there is a perceived risk in attrition or total withdrawal. Instructors identified instances in which students felt discomfort related to the overall theme of organization, and made a concerted effort to reduce those concerns. This perception often influenced the way the course assignments were designed and the environment in which it occurred.

Two main strategies were found. The first was to gauge the learners' possible vulnerabilities and organize the learning experience to mitigate them (thus providing "comfort"). The second was to plan carefully ahead of time, but be flexible as the semester unfolds. 
Organize for comfort. The vulnerabilities of students differed among the teachers and were related to several factors such as the course discipline and age of the learners.

The Composition instructor said that incoming students were more familiar with submitting writing assignments on paper. Therefore, in the beginning of the course, assignments were submitted in this fashion. Starting out in a familiar way helps students focus on the writing itself and "removes the need to figure the electronics out, to figure the computer out and all the technology." Because her students are "still playing around and getting their feet wet, I think it's important to make it [initial tasks] easier and then sort of ramp it up as you go." Note that the assignments are not easier, but rather attention is paid to the method for completing these assignments, with heavy consideration of the learners' technical experience.

The First-Year Seminar instructor also noted that the online learning environment was new to most of her students, so the face-to-face classroom was deemed the more comfortable place to begin the course. She explains, "We do a full week of face-to-face in a computer lab setting so that the students are hands-on learning how to log in to the online CMS [course management system]." Together, they practice navigating through the online portion and completing mock assignments. After the first week, the course slowly becomes more blended. For example, in the second week, students are "on their own, but the faceto-face is their choice to attend.” In this way, the instructor is reducing the barrier of technical experience, while offering a sense of learner autonomy.

The online environment illuminated some comfort factors in the Composition and Spanish courses. Composition students may feel embarrassed about raising their hand in the face-to-face classroom. The online environment "feels safer" because it

Always creates that level of anonymity, that level of comfort, where they can do it on their own time, in their own way.... It allows them that level of invisibility, or at least perceived invisibility, that allows them to, you know, really step back and think about it.

The Spanish instructor emphasizes that some learners, such as "true beginners" might need and benefit from the online environment more. She says, "they need the additional, uh, feedback, they need to practice much more so when they come to classroom, they don't feel real intimidated by the people who are a little bit at a higher level of the language." She notes they have to be "in tune with the language" before coming to the face-to-face class and the online portion helps students interact with the language beforehand. She explains, "When they come to class, they are able not only to produce orally, but they are able to produce in a creative way. They are meaningfully producing in the classroom.” That time online for reflection and practice allows them to come to the face-to-face class prepared. The Composition instructor explains, "They know what we're going to talk about, they know what they're going to do, so it feels much less like I'm surprising them, suddenly springing new stuff on them....they've already had the time to practice and work through it.” The online time simultaneously nurtures a sense of learner autonomy and comfort.

The power of the blended format is the relationship between the face-to-face and online spaces. As the Composition instructor explains, "I can use the face-to-face to clarify, to have that conversation, but then the online can support that and encourage it and so it ends up being just going back and forth between the two." She notes that the blended format provides the support that students need to be better writers, certainly an indicator of student success. She also adds, 
One of the greatest points of success from a student I've ever heard in a blended course was 'I wish we had more face-to-face time.' Just to hear that, to have that student want to meet more because they were so excited about the content, it's just a great feeling.

For the Spanish instructor, success means the meaningful production of Spanish. She says, "I see from my students' outcomes not necessarily that they mastered the language better, but they feel much more comfortable, less intimidated by the language and more willing to produce with the language.”

This shows that while designing a course, it is necessary to gauge what is more familiar to the incoming students (their technical experience, their newness to the course discipline), and design activities/choose environments that maximize this familiarity.

Plan for flexibility. When course design is explored, it is usually conceived as an activity that takes place before the class is actually implemented. As the Spanish instructor says, "It has to be very well-organized before the semester starts." However, any course, especially blended, cannot simply be set up with no further action necessary. The course will ebb and flow, and the instructor's role of modifying the course as needed has a large effect on the learning experience. The Composition instructor explains that "half of teaching is done on-the-fly" to react to what happens in the face-to-face class or online. These instructors emphasized that redesign and changes on-the-fly are to be expected, but students must be kept in the know, otherwise, there is a risk of attrition.

Of the three instructors, the Spanish instructor most strongly emphasizes organization. In order for students to be successful, "It really has to be very, very organized, plan, plan, plan, having [the course] extremely organized for them, so I have to be very organized.” Explaining the weekly organization of her course, she says, "The first part of the week, they are on their own. They know exactly what they have to do...it is very, very methodic." The First-Year Seminar instructor also stresses consistent structure of the course. She says,

There's going to be a consistency and a familiarity. They're more inclined to continue in the process. If you start straying from what they've seen in the first few weeks, they're going to start contemplating if this is still for them, but if you can keep the experience very similar, they're more likely to finish.

The Spanish instructor does acknowledge being flexible as the semester unfolds. She explains, "You have to be very flexible and you have to kind of gauge where the students are." This might require "revision of schedule or revision of material." She emphasizes keeping the students in tune with these changes, or risk student retention. She says,

And as you plan and as you change, students have to again be very comfortable with the format and when you change it, everything, everybody has to be comfortable. If not, students start missing classes and they start feeling not comfortable with the plan so it's not just beforehand, it's beforehand and during.

This association of attrition with disorganization is strong.

Both of these organizational strategies note that students may feel discomfort with change when change is not properly communicated. This can decrease student success, as they define it; students start missing classes or doubt if they can successfully complete the course. 


\section{Communication}

In the "Seven Principles of Good Practice in Undergraduate Education," Chickering and Gamson (1987) identify communication elements in most of their practices. Likewise, communication is a key element in a blended learning course. Through the interviews, it was found that when students perceive communication as lacking, several repercussions ensue. Students may not understand what to expect in a blended course, not feel responsible for their own learning, and not understand how to manage their time. Also, because of resistance toward the particular subject, they may perceive the communication as impersonal or they may be less willing to communicate in general.

Two strategies related to communication were found that enhanced comfort of students: sharing the philosophy and process for the blended course and establishing an atmosphere of mutual feedback.

Share the philosophy and process for the blended course. Because there is no single, universal definition of blended learning (Moskal, Dziuban, \& Hartman, 2013), it is critical for each instructor to explain his or her approach to blending in each course. This includes the course schedule and structure so that students are clear on when they should be present in the classroom and when they should be working online. It also includes communicating the relationship between the face-to-face and online components and the instructor's philosophy of how those two modalities are intertwined.

The Spanish instructor advised, "You really have to be very careful about explaining to each student, because the students have no expectations...you have to really train the students and explain and put a model there for understanding what it means in a blended format.” The First-Year Seminar instructor pointed out that students may not be familiar with the blended format. Her institution uses the term hybrid, which is also used to describe cars, so some of her students questioned what she meant by hybrid. The Composition instructor shared that some of her students did not realize they had registered for a blended course until she explained the structure behind her blended approach.

A clear schedule will help communicate how often one plans to meet and in which setting, but explaining the relationship between the two modalities may be more complex. For example, the Composition instructor expected her students to work through the readings and course content online and then come into class prepared to discuss the material. She explained,

They know what we're going to talk about, they know what we're going to do, so it feels much less like I'm surprising them with suddenly springing new stuff on them. So, if I tell them, 'In class, we're going to be continuing this discussion,' then they've already had the time to practice and work through it.

She continued,

In order for it to be a seamless course that moves fluidly between online and face-to-face, one has to feed into the other so the face-to-face discussion and the talk needed to show up again in online so that the students are like, "Oh yeah, I remember this."

For example, after an in-class discussion she would post her notes online and then use it as a prompt for students' online journal writing assignment. At the same time, she warns,

I can't plan too far ahead because I need to make sure that the online directly references the face-to-face, and then when I walk into the face-to-face class, I need to make reference to their journals, to their discussion online, so that they know that I'm there, that I'm paying attention and the course, and it is really the two parts together. 
Similarly, the Spanish instructor shared that flexibility during the semester is important, and while the blended strategy may not change, the implementation or the schedule may. She explained that this is good practice as long as the changes are clearly communicated. In her words, “...during the semester, because things could happen, things can be, you have to be very flexible...” She continued,

You constantly have to be on top of planning and marketing the planning and make sure the students know it very, very carefully, in every way, in the classroom, online, through announcements, through every way, every way to communicate, communicate, communicate things.

Establish an atmosphere of mutual feedback. Providing feedback to students is more complex and nuanced in a blended course, as it can take place in the face-to-face or online learning environment. In the interviews, instructors offered strategies to make students feel more comfortable receiving, as well as giving, feedback.

Leaving feedback for online assignments and participating in online discussions is done with care. Once the Composition instructor begins incorporating online writing assignments, she is especially careful with her feedback. "With online feedback, the content can be exactly the same, but it will always feel less personal." She changes the color from black to purple, "partially to differentiate my text from theirs, but it's also to make it feel more personal." This small action can be especially salient in a composition course, where she notes, "They're resistant to writing, so anything we can do to minimize that fear...half of what we're trying to do is break down the intimidation factor that comes with writing." While she perceives online feedback to be viewed as impersonal, she notes that the online discussion can pose more of a safe place than the face-to-face classroom:

Students are much less likely to have fully engaging conversations in the classroom, and I think it's part of that safety issue, that sense of comfort or risk...if they are engaged in the online class, people are commenting, they are responding to each other, they are answering questions, and it seems much more active.

However, students might not be comfortable with active online discussion involvement from the instructor. She notes, "If I post early, then it kind of silences the conversation." Instead, she peppers comments here and there, to let them know she is present. It seems that students are vulnerable regarding teacher communication in the online venue, and so engaging in modest, personal, careful feedback is best.

Instructors leveraged other tools to provide feedback as well. The Spanish instructor lauded the feedback provided by the online Spanish program. She said, "The good thing about the online environment is that the students are able to get immediate feedback...immediately they're able to see their errors, and can repeat exercises as much as they want." This is helpful in her discipline where students walk in saying, “Here, teach me. I'm monolingual. I can't do languages....now the students, before they come to class, have to be somehow in tune with the language and have to interact with the language.” The Composition instructor leveraged the early warning system at the school to alert her to students' activity, noting that she sends out messages of positive reinforcement, as well as those checking in with students who have not turned in assignments.

Providing feedback related to at-risk behavior can be contentious. The Composition instructor preferred the face-to-face environment, because online, "it's sometimes hard to motivate that student, it's hard to reach them, you don't [know] where they are or what they're doing.” By comparison, the face-toface setting is where "you can grab a student and say 'hey, you really need to step up'." The First-Year Seminar instructor subtly selected both environments, explaining 
I try to reach them where I think I can most easily get to them...if I catch the student in a face-toface environment, I will say 'I posted something online private for you and I need you to see it and then we can talk about it next time you're in class'.”

Although seemingly preferring the face-to-face environment for contact, the Composition instructor notes, “Once I started sending out emails saying 'we really need to make this happen,' then it improved.” Reflecting on these practices, both environments can be used together to reach out to students and both can be effective.

It is important to establish that feedback should be a two-way process, and that students feel comfortable to give feedback on the course. The Composition instructor was designing the course as the course unfolded, and she said,

They knew right from the start they were in a new course, so I really worked on making sure they felt comfortable talking to me about what was going on in this class...they need to feel comfortable enough to me to say, 'This is not working,' so I can make adjustments.

The First-Year Seminar instructor said, "At the end of each session, we ask for the students' feedback and how this experience was."

When providing feedback online, pay attention to how it is presented. When participating in online discussions, participate modestly. Select online software that can facilitate student feedback in a safer, more comfortable manner. The online environment can be a place to communicate, but approaching a student face-to-face is a necessary component for discussions of student performance. Finally, explicitly soliciting student feedback is key to ensuring that students feel comfortable.

The two communication strategies shared here show that students may feel discomfort when they perceive communication as lacking. This can deplete student success, as they do not know what to expect, how to manage time, or misinterpret teacher feedback.

\section{Support}

Each new group of students brings a wide array of experiences with online learning and technology to the first day of class. The interviewees expressed concerns about students who may be new to the online environment, those who may lack the self-discipline to work independently, or those who may struggle with the technology itself. Several strategies emerged to support students as they build these skills and help mitigate the fears associated with them. They ranged from scheduled office hours and how-to guides to technical support services and early identification of at-risk students. These support strategies are intended to minimize the external barriers to success and put students more at ease so that they can focus on the course content and the tasks associated with learning more than the delivery mechanisms.

Provide face-to-face support during scheduled "online time." One of the conveniences of blended courses is the reduced classroom seat time. Two of the interviewees described some variation of using that scheduled time that would have been classroom meeting time to offer optional face-to-face support. For example, the Spanish instructor acknowledged that most of the student population she serves work full time and they have difficulty meeting with her before or after class. If Spanish were delivered as a traditional classroom course, she would have met with her students two days a week. When structuring her blended course, she decided to meet formally one day a week with the understanding that the online assignments would replace the second class meeting each week. However, she used that second timeslot each week as an optional meeting time where students could come in and meet with her individually or in small groups to practice pronunciation, review for a test, or interact on a more personal level. 
Similarly, the First-Year Seminar instructor provided optional face-to-face support during the reduced seat time of her course as well, but she mixed it up a little more. Some weeks she required the students to come in and meet in the computer lab; some weeks she required students to come in for one session but they could choose which day they wanted, and other weeks it was completely optional to come into the classroom. She was concerned about student confidence and comfort with navigating the online course materials, so her strategy was to provide additional face-to-face help during the optional class meetings as well as office hours. She was also concerned about students' self-discipline and time management skills, so she strongly encouraged them to use the scheduled optional class time to complete the online assignments if they chose not to come in. Overall, her main goal was to make sure "the students know that support is there if they need the face-to-face [time].”

Take advantage of institutional support services. Another strategy that emerged was to make use of existing support services on campus, for both students and faculty. It may be intuitive to assist students with technological barriers, but often that is not the instructor's area of expertise. Working with colleagues and campus resources alleviates the pressure to be a technology expert and allows the instructor to focus more on the processes of teaching and learning. For example, the First-Year Seminar instructor was very concerned about students getting lost in the online environment. To be proactive, she described how she "collaborated with [their] online course management guru" in the design of the online components of her course to make sure students could easily navigate the system. During the semester, she also encouraged her students to visit the academic advisement center for assistance because their entire staff was able to help students. In addition, she described a second group, "an entire office that is dedicated to the technological support of online students," that she sends students to for "walk-in" technical support. Because her students are predominantly new to online coursework and she was concerned about their experience with the technology, the First-Year Seminar instructor went even one step further and developed "how to" handouts with step-by-step instructions and screenshots to assist them with navigating the online system.

The Composition instructor was more concerned about the self-discipline required to be successful in a blended class. Some of her students lacked follow through in the online assignments and what she describes as "that element of preparation" for the face-to-face classes. She worked with an online learning student support specialist who reaches out by phone to assist and encourage students who are not demonstrating progress online. In addition, she also advocated working with faculty support services such as her director of online learning and warns others, "Don't overlook the personnel at your institution." She expressed a concern that many faculty members view them as technical experts, but she added that they also "study best practices all the time and are great resources."

The strategies in this section address two types of support concerns: technical support with the online coursework and instructor support with the course content. The blended format provides additional flexibility for the instructor to assist students who need extra face time, which leads to a more studentcentered environment. Also, instructors do not need to provide all the support on their own. Every organization is structured differently, so it is important to seek out institutional resources and make use of support services whenever possible.

\section{Discussion}

In interviews with three community college instructors, "comfort” was identified as mitigating student vulnerabilities and smoothing out roadblocks that hindered student learning and success. 
Once the data analysis was complete, it was realized that while the concept of "support" is foundational to the instructor goal of student-perceived "comfort," it is fundamentally, an outgrowth of the interplay between the various organization and communication strategies identified. Thus, while the model presented earlier depicted organization, communication, and support equally contributing to comfort while comfort gave rise to student success, the revised model (Figure 2) presents support as a fuzzier, more open concept with less defined boundaries. In fact, the oval labeled "support" has been redrawn with a dotted rather than solid outline. Organization and communication are positioned within the bounds of the support oval and are shown with multiple associated strategies in interplay with each other. The remainder of the revised model remains unchanged. Student success is still the end point with comfort serving a mediating function between support and this success goal.

The instructors interviewed were all "deemed" successful blended course instructors at their institutions and frequently present at educational conferences. Also, all three instructors worked at the community college level and are focused on teaching and learning. Finally, all three disciplines fall into the realm of general education courses that students encounter during their first two years in higher education.

As previously mentioned, the findings were grouped around organization, communication, and support and are reported as pedagogical strategies and scalable best practices for the design of blended courses that promote student success.

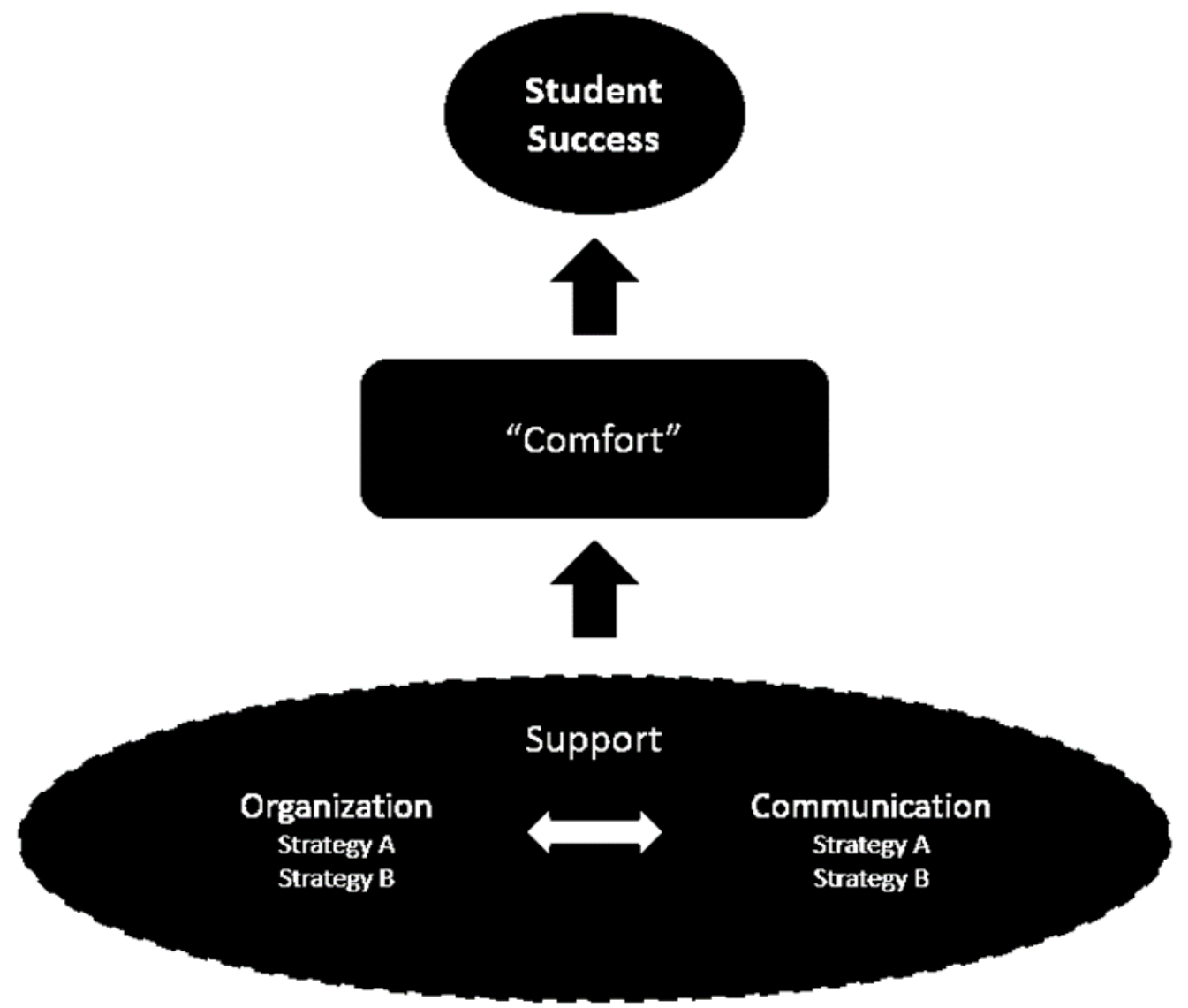

Figure 2. Modified comfort model 
In the first finding for organization, each of the disciplines addressed vulnerability for students: fears of entering higher education, writing, and learning a second language. The instructors used the blended design to address these "stress points" and to create an environment that promoted student "comfort" that lead to student success. Although each instructor used a different method to scaffold student success, all the methods focused on creating a level of "comfort" to build student confidence and mitigate student vulnerabilities. The second organization finding was to carefully plan the integration between the face-to-face and online environment and to create a course with consistency and clarity for the students. However, flexibility must be incorporated into the design to allow "on the fly" changes to keep the course aligned with changing student needs and current events. A key factor in the flexibility component was communicating all changes to students through all means available.

Each instructor created a unique course design to fit their discipline and teaching style. Sharing their teaching philosophy and their blended course design was the first finding for communication. It is important for students to understand the course design, connection between the face-to-face and online environments, and instructor expectations. Also, there needs to be continuous communication of the course design throughout the course. The second communication finding was creating an atmosphere of mutual feedback that includes both feedback on student assignments and feedback from students to the instructor. There were suggestions for making online feedback to students more personal, how to interact in discussions, automated feedback, and where to provide the feedback. Also, the instructors recommended creating opportunities for students to provide feedback about the course and freedom to let the instructor know when something wasn't working.

Although all the findings provided student support, there were some findings more directly related to support. These findings identified ways to help students build technical and soft skills required to be successful in an online environment. All three instructors reduced the amount of face-to-face meeting time in their courses. Therefore, the first finding revolved around the unused meeting time. One suggestion was to use this time as office hours to provide support for students. Another was a timemanagement strategy for students to use this time to work on their course. The second finding involved using institutional services to support both faculty and students. Faculty should look for experts within their institution to help with the design of their blended courses. For students, institutions have a variety of support resources that may be leveraged for blended courses.

Blended courses tend to be unique to the discipline and instructor. At the same time, these strategies may be employed and tweaked to fit most courses. For example, a quick way to communicate the design of a blended course is to include a statement in the syllabus. This statement alerts students that design of the course is different than others they may have encountered.

\section{Conclusion}

This study is significant in its discovery of the concept of "comfort.” Each instructor intentionally used the blended design of her course to build student support. However, their designs go beyond the routine student support strategies and demonstrate thoughtful strategies to build student confidence over the span of the course. The concept of intentionally building strategies to bolster student confidence during the learning process should be included in faculty development. Also these strategies should be considered by professionals mentoring teachers new to blended and online courses and would be a step beyond designing for a specific curriculum.

As noted previously, the three instructors selected for interviewing in this study were chosen because of two commonalities (i.e., community college setting and referral as an effective blended learning instructor) and two differences (i.e., teaching at different institutions and within different 
disciplines). By making this purposive selection, we were looking for emergent themes to be explored within the current study. It is not our intention to present these findings as generalizable to the population of all community college faculties or even to all community college English composition faculties. Rather, applications to contexts other than those of the three instructors in this study are left to the reader to determine. Like Stake and Turnbull (1982) we have intended to provide enough "detailed description necessary to generate vicarious experience for readers, then allowing the development of naturalistic generalizations" (p. 3) to contexts other than those of our interviewees. Further, we recognize that there is "no one 'correct' interpretation" (Janesick, 2000, p. 393). So, while we hold with Janesick (2000) that "reliability in the traditional sense of replicability is pointless here" (p. 394), it is our hope that readers find this study credible, that a fit between our explanations and the details of the interviews we have provided is compelling. Indeed we agree with Creswell and Miller (2000) that "qualitative inquirers need to demonstrate that their studies are credible” (p. 124; emphasis added).

Additional rigorous studies of specific blended learning contexts are encouraged. Qualitative methods (such as the interview-based cases in this study or other types) are likely to yield insights more nuanced than, for instance, merely surveying a large number of blended learning instructors. Many more studies will be necessary for meaningful patterns to take shape. While it is more challenging to systematically implement blended programs institutionally (Cavanagh, Thompson, \& Futch, in press), more could be learned about the function of individual blended learning courses. For example, it appears from this study that courses serving a strategic, gatekeeping function might benefit from the affordances of the blended modality. Subsequent studies should explore this further both in the community college and in the university context.

\section{References}

Bailey, T., Calcagno, J.C., Jenkins, D., Kienzl, G., \& Leinbach, T. (2005). Community college student success: What institutional characteristics make a difference? CCRC Working Paper \#3. Retrieved from http://files.eric.ed.gov/fulltext/ED489096.pdf

Brotton, J. (2005). The evolution of a hybrid course. Inquiry, 10(1), 14-19.

Cavanagh, T.B., Thompson, K., \& Futch, L. (in press). Supporting institutional hybrid implementations. In Linder, K. and Fontaine, D. (Eds.). New directions for teaching and learning: Hybrid teaching and learning. Jossey-Bass: New York, NY.

Chickering, A. W., \& Gamson, Z. F. (1987). Seven Principles of Good Practice in Undergraduate Education, AAHE Bulletin, 3-7. Retrieved http://files.eric.ed.gov/fulltext/ED282491.pdf

Cohen, A. M., \& Brawer, F. (1996). The American community college. San Francisco: Jossey-Bass: New York, NY.

Crawford, C., Barker, J., \& Seyam, A. (2014). The promising role of hybrid learning in community colleges: Looking towards the future. Contemporary Issues in Education Research, 7(3), 237-242.

Creswell, J. and Miller, D. (2000). Determining validity in qualitative inquiry. Theory Into Practice, 39(3), 124-130. 
Cruz-Johnson, C. (2012). Success and persistence of learners in a blended developmental reading course at an urban community college (Doctoral Dissertation). Capella University, Minneapolis, Minnesota.

Dembicki, M. (2011). Hybrid courses gaining steam. Community College Daily, American Association of Community Colleges. Retrieved from http://www.ccdaily.com/Pages/Technology/Hybridcourses-are-gaining-steam-at-colleges.aspx

Garman, D. E. (2012). Student success in face-to-face and online sections of biology courses at a community college in east Tennessee. Electronic Theses and Dissertations. Paper 1408. http://dc.etsu.edu/etd/1408

Halverson, L. R., Graham, C. R., Spring, K. J., Drysdale, J. S., \& Henrie, C. R. (2014). A thematic analysis of the most highly cited scholarship in the first decade of blended learning research. The Internet and Higher Education, 20, 20-34. doi:10.1016/j.iheduc.2013.09.004

Hartman, J., Moskal, P., \& Dziuban, C. (2005) Preparing the academy of today for the learner of tomorrow. In Oblinger, D. and Oblinger, J. (Eds.), Educating the Net Generation: An EDUCAUSE e-Book. Retrieved from http://www.educause.edu/library/resources/preparing-academy-todaylearner-tomorrow

Hijazi, S.., Crowley, M., Smith, M.L., \& Shaffer, C. (2006). Maximizing learning by teaching blended courses. Proceedings of the 2006 ASCUE Conference.

Janesick, V. (2000). The choreography of qualitative research design: Minuets, improvisations, and crystallization. In Denzin, N. and Lincoln, Y. (Eds). Handbook of Qualitative Research. Sage Publications: Thousand Oaks, CA.

Johnson, L, Adams, S., Cummins, M., Estrada, V., Freeman, A., \& Ludgate, H. (2013). Technology Outlook: Community, technical and junior colleges 2013-2018: An NMC Horizon Project sector analysis. Austin, TX: The New Media Consortium.

Lai, M., Lam, K. M., \& Lim, C. P. (2016). Design principles for the blend in blended learning: a collective case study. Teaching in Higher Education, 1-14.

Lloyd-Smith, L. (2010). Exploring the advantages of blended instruction at community colleges and technical schools. MERLOT Journal of Online Learning and Teaching, 6(2), 508-515.

Ma’arop, A. H., \& Embi, M. A. (2016). Implementation of blended learning in higher learning institutions: A review of literature. International Education Studies, 9(3), 41-52.

Manuelito, S.H. (2013). Self-regulated learning in a hybrid science course at a community college (Doctoral Dissertation). Arizona State University, Tempe, Arizona.

McGee, P., \& Reis, A. (2012). Blended course design: A synthesis of best practices. Journal of Asynchronous Learning Networks, 16(4), 7-22.

Moskal, P, Dziuban, C., \& Hartman, J. (2013). Blended learning: A dangerous idea? Internet and Higher Education, 18, 15-23. 
Porter, W. W., Graham, C. R., Spring, K. A., \& Welch, K. R. (2014). Blended learning in higher education: Institutional adoption and implementation. Computers \& Education, 75, 185-195.

Shand, K., Glassett Farrelly, S., \& Costa, V. (2016). Principles of course redesign: A model for blended learning. In Proceedings of Society for Information Technology \& Teacher Education International Conference 2016 (pp. 378-389). Chesapeake, VA: Association for the Advancement of Computing in Education (AACE). Retrieved from https://www.learntechlib.org/p/172311.

Shea, P., \& Bidjerano, T. (2014). Does online learning impede degree completion? A national study of community college student. Computers \& Education, 75, 103-111.

Stake, R.E., \& Trumbull, D.J. (1982). Naturalistic generalizations. Review Journal of Philosophy and Social Science, 7, 1-12.

Traver, A. E., Bidjerano, T., \& Shea, P. (2014). Correlating community college students' perceptions of community of inquiry presences with their completion of blended courses. Internet and Higher Education, 20, 1-9.

Wallace, L., \& Young, J. (2010). Implementing blended learning: Policy implications for universities. Online Journal of Distance Learning Administration, 13(4).

Wolff, B. G., Wood-Kustanowitz, A. M., \& Ashkenazi, J. M. (2014). Student performance at a community college: Mode of delivery, employment, and academic skills as predictors of success. MERLOT Journal of Online Learning and Teaching, 10(2), 166-178.

Xu, D., \& Jaggars, S. S. (2011). Online and hybrid course enrollment and performance in Washington State Community and Technical Colleges. Community College Research Center, Teachers College.

Yen, C., \& Liu, S. (2009). Learner autonomy as a predictor of course success and final grades in community college online courses. Journal of Educational Computing Research, 41(3), 347-367. 